\title{
Pathologies - Incompatibility of Materials and Human Intervention in a Historic Building of Elvas
}

\author{
Rui Manuel Henriques Franco da Silva ${ }^{1}$ \\ António José Morais ${ }^{2}$ \\ Soheyl Sazedj ${ }^{3}$ \\ Maria Teresa Pinheiro-Alves ${ }^{4}$
}

T 8

ABSTRACT

Preserving and safeguarding the identity and original authenticity are targets to accomplish, in an action of conservation, restoration or rehabilitation of buildings, taking into account that interventions respect the values of compatibility, adaptability and reversibility. Any intervention that takes place in a historic building, will depend on a historical survey which ideally includes the knowledge of the origin, the building design, materials and construction techniques used, building's occupants and constructive interventions realized.

In a historic building, such as the military building called "Governor's House of Square" in Elvas, after identifying the constructive anomalies and their causes, it has been found that human action was preponderant, because of vandalism and posterior constructive interventions.

Some pathology identified are as, anomalies in the coating or failure in a lintel of the exterior wall. In the first case the anomalies are certainly due to incompatibility between the support material and the coating, because of the exposure to thermal amplitude. The admissible correction in this case will be the removal of the coating, exposure of hidden masonry and implementation of a compatible coating based on lime and sand. The later case shows that mechanical action involved has exceeded the capacity of flexural strength of the lintel. The posterior opening of the entrance caused changes in the distribution of vertical loads and consequently provoked the failure. In an attempt to preserve the building and the testimony of many years, it seems to be of interest to maintain the entrance and instead to replace the lintel adequately in material and dimension.

KEYWORDS: Incompatibility of Intervention, Historic Buildings, Rehabilitation

\footnotetext{
${ }^{1}$ Postgraduate Student of Advanced Studies on Recovery of Historical Patrimony and Urban and Economic Regeneration, the Faculty of Architecture of the University of Lisbon in association with the University of Évora, University of Extremadura and the Polytechnic Institute of Portalegre, PORTUGAL, ruifrancosilva@gmail.com

${ }^{2}$ Faculty of Architecture - University of Lisbon, Department of Technology, Lisbon, PORTUGAL, ajmorais@,fa.ulisboa.pt

${ }^{3}$ Faculty of Architecture - University of Lisbon, Department of Technology, Lisbon, PORTUGAL, sazedj@,fa.ulisboa.pt

${ }^{4}$ University of Évora, School of Sciences and Technology, Dep. of Rural Engineer, Évora, PORTUGAL, tpa@uevora.pt
} 